\title{
THE DIAGNOSIS AND TREATMENT OF EARLY POLIOMYELITIS.
}

\author{
By A. GORDON SIGNY, M.B., B.S. (Lond.), \\ Assist-Pathologist, Hospital for Sick Children, Gt. Ormond Street.
}

Although there have been no large epidemics of poliomyelitis in this country, such as have occurred in America and Australia, the disease is endemic and is not only ever with us, cropping up sporadically, but on occasion minor epidemics have been met with in Public Schools and similar Institutions. It is no doubt for this reason that it is as a rule only diagnosed after paralysis has set in, and it is with rare exceptions, even during the course of these minor epidemics, that it is ever recognised in the pre-paralytic stage. But since it is only during this earliest phase of the disease that treatment is of any avail, it is essential that in any unexplained febricula the possibility of poliomyelitis should be kept in mind. In America and Australia so much public interest has been aroused in the matter that many cases are diagnosed in the pre-paralytic stage and there is no doubt that the same would happen in this country, if the medical profession had a knowledge of the signs and symptoms of the early stages of the disease.

The clinical picture at the onset is subject to wide variations but three main types can be recognised.

(I) Very rarely there may be no prodromal symptoms and the disease sets in with sudden paralysis.

(2) The gastro-intestinal type. Here, there is vomiting and diarrhœa with fever followed by a remission during which the patient appears to be perfectly well : then a relapse with recurrence of the systemic symptoms plus certain nervous manifestations which lead on to paralysis.

(3) The commonest type is that shewing systemic infection leading straight on to nervous infection.

\section{Symptoms.}

The general systemic symptoms consist of headache, fever and vomiting with mild upper respiratory manifestations, such as nasal catarrh, together with occasional constipation but more commonly diarrhœea. Fever is a very constant feature of the disease and readings are generally $100^{\circ}$ to $104^{\circ} \mathrm{F}$. Profuse sweating is also very common. Headache is a very frequent complaint and it is associated with pains chiefly in the neck but also in the bones, abdomen or the extremities. In the more severe cases there is definite stiffness of the neck due to meningeal irritation, combined with drowsiness alternating with extreme restlessness and irritability. One especial sign is the stretching of the mouth in the endeavour to raise the head off the pillow. In meningitis the patient is usually too drowsy to respond when asked to raise his head, but in poliomyelitis he is more rational throughout and will try to lift his head from the pillow but finds that he cannot.

The reflexes are at first exaggerated and then, if paralysis is to follow, they become diminished and finally lost. Quite commonly, hyperæsthesia can be demonstrated by the lightest touch over the spine and the larger nerve trunks. 
Paralysis then sets in and is most common on the second and third days, but it may be delayed for as long as the eighth day. The implication of practically every muscle or combination of muscles has been observed.

These general symptoms rarely occur together and they seem to vary from time to time and from epidemic to epidemic. In some, for instance, the prodromal symptoms may be confined to limb pains and profuse sweating, while in others the meningeal symptoms predominate.

\section{Clinical Types of the Disease.}

(I) The Abortive Type which obviously is only likely to be recognised during an epidemic. In such cases any combination of the symptoms of the general systemic disease may occur but there are no paralyses.

(2) The Non-Paralytic Type. This variety is much easier to recognise than the abortive type. In this class of case the above-mentioned systemic symptoms may occur, together with definite meningeal irritation. This should always lead to an examination of the cerebro-spinal fluid, when the diagnosis will probably be established. There are, of course, no paralyses in this type of the mischief.

(3) The Type with Subcortical Paralysis. This is the usual form of the disease and on about the third day there is definite evidence of paralysis following upon a previous hyperæsthesia, pains in the limbs and weakness. Some of these cases can be extremely severe with ascending mischief leading to bulbar paralysis, paralysis of the diaphragm and occasionally death.

(4) The fourth variety is the Cerebral or Encephalitic Type which may resemble exactly encephalitis lethargica. In these cases there are no paralyses and the anterior horn cells which are usually affected seem to escape.

(5) The fifth type is a rare type, which shows mainly a taxic symptoms and is due to involvement of the cerebellum.

Occasionally after paralysis has set in, and the disease has become quiescent, there is a sudden rise of temperature associated with a further extension of the disease. It is not definite whether this is a true relapse or simply an extension of the disease with exacerbations and spreading paralysis.

\section{Laboratory Aids to Diagnosis.}

The most important investigation to be carried out is Lumbar Puncture, and the advisability of performing this simple operation in all doubtful cases cannot be too strongly urged. The operation will in all probability be performed in those cases with marked cerebral symptoms, but it is just as important in the less severe examples in which valuable prophylaxis can be instituted.

The fluid obtained is, as a rule, quite clear but it is always under increased pressure. There is an increase of cells, cell-counts varying from to to I,000 cells per c.mm. being recorded. The differential count has been the subject of much argument. In my experience it is always a mono-nuclear increase and most of 
the reported cases have shewn a pure lymphocytosis. Cases have been recorded, however, which show as many as 50 per cent. or even more of the cells to be polymorphs, and thus a high proportion of polymorphs does not necessarily rule out a diagnosis of poliomyelitis. Various workers, too, have described a change over in the type of cell from an early polymorph increase to a mononuclear count as paralysis sets in. The concensus of opinion is that a mononucleosis is the rule, but that a special type of reaction may result in a polymorph increase.

The protein is usually increased and may even reach a figure of .04 or .05 mgs. per cent. The protein-cell ratio is not a constant. On the other hand, the chlorides remain normal throughout: the sugar content is also normal, or only slightly increased, and smears and cultures are negative.

The only other change described in the cerebro-spinal fluid, and which is said to be constant, is some alteration in the colloidal gold reaction. The change usually occurs in the neighbourhood of the syphilitic zone but never reaches a figure higher than three, the usual type of curve being II22II0000. It is said that even in very mild cases of poliomyelitis which exhibit no other definite changes in the fluid, Lange's test will be positive.

Examination of the blood occasionally reveals a leucocytosis up to 20,000, generally with a lymphocytosis in the early days and a polymorphonuclear leucocytosis at the end of the first week which may amount to 80 per cent. These changes, however, are not constant.

\section{Differential Diagnosis.}

In this communieation the differential diagnosis in the pre-paralytic stage, of course, is alone considered.

(I) Purulent Meningitis. In the early stages of meningococcal or other septic meningitis the differential diagnosis from poliomyelitis may be difficult clinically, but the C.S.F. will shew firstly, a very high cell count with the polymorphs predominating, secondly, a low sugar content and thirdly, the causal organism can be demonstrated.

(2) Tuberculous Meningitis. In the early stages it may be extremely difficult to differentiate this condition from poliomyelitis. In meningitis, however, the patient is less rational and the onset tends to be more insidious, while the characteristic features in the C.S.F. are the very early drop in the chloride content and Tater on the cob-web clot and the lowered sugar content.

(3) Meningism. The irritation of the meninges associated with pneumonia and other febrile conditions may be mistaken clinically for poliomyelitis, but in this state of matters the cerebro-spinal fluid shews no abnormality except perhaps a slight increase in pressure. Meningeal irritation following mastoiditis is readily distinguished by the previous history and a very high cell count (of which 90 per cent. or more are polymorphs) of the C.S.F.

(4) Encephalitis Lethargica. The differential diagnosis of this condition from poliomyelitis is sometimes impossible, as the clinical pictures and the cerebro-spinal fluid findings may be practically identical. During the course of an epidemic the differentiation is easier and also during the later stages, since the acute mischief in poliomyelitis is usually over by eight days whereas in lethargic encephalitis this may continue for several weeks. 


\section{Prognosis.}

Death in poliomyelitis, when it occurs, is nearly always due to paralysis of the diaphragm or intercostals or both, leading to immediate death in the severe examples and death from pneumonia in the milder. From a survey of $\mathrm{I}, 848$ cases Ruhrah and Mayer ${ }^{(1)}$ shewed that 8I per cent. of the deaths from poliomyelitis occur during the first week, the third and fourth days revealing the maximum mortality. Prognosis concerning the residual paralysis does not enter within the scope of this paper.

\section{Treatment.}

A.-Prophylaxis. It is recommended that a dose of $20 \mathrm{c.cm}$. of pooled convalescent serum should be given intramuscularly during an epidemic. Experimentally this passive immunity lasts from two to three weeks and hence the injection should be repeated, if serum is available, throughout the epidemic at this interval. Amongst a group of several hundred children, Park, during the I93I epidemic in New York ${ }^{(2)}$ obtained an immunity in all but three cases who, however, developed only a mild attack. Many other workers have obtained equally satisfactory results.

B.-Curative treatment. (I) General measures consist of rest in bed, light diet combined with elimination treatment and sedatives. Care must be taken with the nasal secretions in which the virus has been shewn to be abundant.

(2) Drugs. Of all the drugs used hexamine is the only one that is known to possess any value in averting or reducing paralysis. Adrenalin has been used intraspinally to reduce œdema which may be causing widespread paralysis. It has been used a great deal in varying doses, from I to $300 \mathrm{c.cms}$. of I/I,000 dilution with different degrees of success. It certainly seems to reduce the œedema and may thus limit to a certain extent the paralysis. Hypertonic saline given intravenously has been shewn experimentally by Weed and his colleagues ${ }^{(3)}$ to reduce the total volume of the C.S.F. and to lower the pressure. They recommend roo to $200 \mathrm{c} . \mathrm{cms}$. of a 25 per cent. solution repeated every twelve to twenty-four hours. A more recent improvement is hypertonic glucose saline solution.

(3) Lumbar puncture is strongly to be recommended as a routine measure in all doubtful cases for, apart from the help in diagnosis, this operation in itself, by reducing the C.S.F. pressure, often appears to have a markedly beneficial effect; in fact, most observers agree that there always results an immediate improvement of symptoms.

(4) Serum therapy with Convalescent Serum. Serum from convalescent patients was first used in the treatment of poliomyelitis in I9Io, and controversy has raged round it ever since. The serum is obtained in the following manner. Convalescents from the disease are bled and the serum separated off. A W.R. is done, phenol added as a preservative, the serum is filtered through a bacterial filter, sterility tests applied and then ampouled ready for use.

The route of administration varies with different workers. The original route, and still the method of choice with many, is that via the spinal canal, and doses of 20 to $60 \mathrm{c} . \mathrm{cms}$. are recommended. Intravenous and intramuscular injections have 
also been widely used, the latter with very good results. All workers, however, are agreed that the serum is only of value in the pre-paralytic stage, or at the latest twenty-four hours after the onset of paralysis. After this, it would seem to have no curative value. This is in accord with all diseases treated with convalescent serum, e.g., as in measles, where convalescent serum is efficient only in the early part of the incubation period and, owing to the relatively small amount of antibody present, is of no value in the treatment of the established disease.

Macnamara in Australia ${ }^{(4)}$, maintains that the serum should not be prepared, i.e., that no preservative should be added. It is held that the blood should simply be carefully and aseptically taken, filtered and ampouled. It is said to keep well in the ice-chest for over a year and because of the absence of phenol, produces no meningeal irritation. This irritation has been observed by many workers and consists of an intensifying of the symptoms within twenty-four hours after the injection. The cerebro-spinal fluid at this stage will shew a much increased cell-count with a high percentage of polymorphs.

Macnamara's routine, adopted in Australia, is to give 50 c.cms. or more, intraspinally and intravenously as soon as the diagnosis is confirmed from an examination of the cerebro-spinal fluid. The temperature falls very quickly but if it has not fallen in eighteen hours the administration of the serum is repeated, 30 to $40 \mathrm{c} . \mathrm{cms}$. being given intravenously. There is no danger of anaphylaxis or serum disease as the serum is homologous. If the patient is seen within twentyfour hours after the onset of paralysis, and there is still fever, Dr. Macnamara recommends giving 40 to $60 \mathrm{c} . \mathrm{cms}$. of serum intravenously, which usually results in an immediate fall in temperature and arrest of paralysis. She never gives serum to paralysed patients with a normal temperature. Her results are excellent, but unfortunately there was no control series, and she admits that the only way in which controls could be obtained would be to treat alternative cases with serum and leave the others, but this is always a very real difficulty in the treatment of a serious disease with a vaunted remedy.

In America, there are wide differences of opinion on the value of serum therapy. I cannot, in the space allowed, detail all the points of view and will content myself by quoting two divergent sets of results.

A.-Results obtained in Manitoba Epidemic, 1928. (5)

\begin{tabular}{|c|c|c|c|c|}
\hline & Treatment Adopted. & $\begin{array}{l}\text { Total } \\
\text { Cases. }\end{array}$ & $\begin{array}{l}\text { Number } \\
\text { Recovered. }\end{array}$ & $\begin{array}{l}\text { Number with } \\
\text { Residual } \\
\text { Paralysis. }\end{array}$ \\
\hline I. & $\begin{array}{c}\text { One dose } 25 \text { c.cms. intramuscularly } \\
\text { (preparalytic) }\end{array}$ & 57 & 53 & 4 \\
\hline 2. & $\begin{array}{l}\text { Two or more doses intra- } \\
\text { muscularly (preparalytic) }\end{array}$ & I7 & I6 & I \\
\hline 3 . & 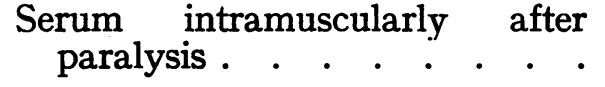 & 33 & 7 & I5 \\
\hline 4. & No serum & 54 & I4 & 34 \\
\hline
\end{tabular}

The conclusions reached were that at least 20 to $25 \mathrm{c} . \mathrm{cms}$. of serum should be given at the onset, but that this measure was only of value in the pre-paralytic 
cases. The temperature should be used as the guide for further treatment: if this is over roo degs. Fahrenheit at the end of eighteen hours, the injection should be repeated.

B.-New York Epidemic, I93I : 927 cases summarised by Park. ${ }^{(2)}$

(Results in all cases after six months).

\begin{tabular}{|l|c|c|c|c|c|}
\hline & $\begin{array}{c}\text { No. of } \\
\text { cases. }\end{array}$ & $\begin{array}{c}\text { Complete } \\
\text { Recovery. }\end{array}$ & Weakness. & Paralysis. & Death. \\
\hline Control series . . & 406 & $80.3 \%$ & $7.3 \%$ & II.I\% & I.2\% \\
\hline Treated with serum & 503 & $76.5 \%$ & $8.9 \%$ & I0.5\% & $4.0 \%$ \\
\hline
\end{tabular}

These results from New York shew no difference between the treated and the untreated cases, and we are left rather in a dilemma as to whether to advise convalescent serum therapy or not. These two lots of divergent results suggest that there must have been differences either in the epidemics, in the type of virus or in the serum used. It should be borne in mind, however, that Park's results are the first to be properly controlled, inasmuch as in previous epidemics all preparalytic cases were treated and it may be assumed that some of them at any rate would have been abortive and non-paralytic and thus give a good non-paralytic rate even without any serum therapy. However, in spite of these provisoes, I would strongly recommend that children seen during an epidemic, particularly those shewing any nervous symptoms, should be given the benefit of the only specific treatment available, more especially since the injection can be given intramuscularly.

A horse serum has been successfully prepared and has given good results in certain hands. So far, it has been difficult and expensive to prepare and cannot very well be used intrathecally owing to the meningeal irritation it sets up. It should also not be given intravenously for fear of anaphylaxis, which leaves us with the intramuscular route as the only alternative. So far, we have had quite good results by this method in the few cases treated, and this can be continued with convalescent serum given intrathecally.

One last point I should mention is the treatment of paralysis of the diaphragm and intercostals by means of Drinker's apparatus ${ }^{(6)}$. This consists of a respirator by which the patient is artificially kept breathing for long periods until the muscles recover from the paralysis. Many successes have been reported from America and patients, who would otherwise undoubtedly have succumbed, have been tided over until their normal respiratory function has been restored.

REFERENCES :

(1). Ruhrah, J. and Mayer, E. E. "Poliomyelitis in all its aspects", Philadelphia, 1917.

(2). Park, W. H. and Committee. "Poliomyelitis", International Committee, 1932.

(3). Weed, L. H. and Colleagues. Am. J. Physiol. 58: 53, 85, 101.1921.

(4). Macnamara, J., Med. J., Australia, 18: 386. 1931. Macnamara, J. and Morgan, F. G., Lancet 1 , 469, 527. 1932.

(5). McEachern and others. Canad. M.A.J. 20, 369. 1929.

(6). Drinker, P. J.A.M.A. 92, 1658.1929. 